\title{
A Prospective Review on the Encapsulation of Bioactive Compounds
}

ISSN: 2640-9208

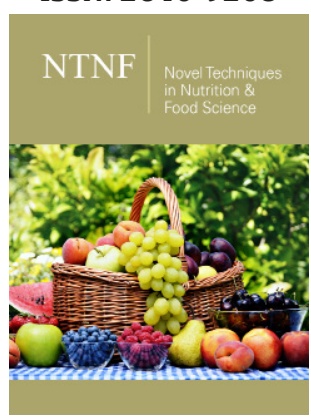

*Corresponding author: Josiana Moreira Mar, Laboratory of Nanostructured Polymers (NANOPOL), Federal University of Amazonas, Brazil

Submission: 眥 August 02, 2021

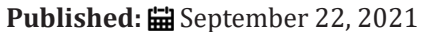

Volume 6 - Issue 2

How to cite this article: Josiana Moreira Mar, Matheus Moraes Biondo, Edgar Aparecido Sanches, et al. A Prospective Review on the Encapsulation of Bioactive Compounds. Nov Tech Nutri Food Sci. 6(2). NTNF. 000631. 2021. DOI: $10.31031 / N T N F .2021 .06 .000631$

Copyright@ Josiana Moreira Mar. This article is distributed under the terms of the Creative Commons Attribution 4.0 International License, which permits unrestricted use and redistribution provided that the original author and source are credited.

\author{
Josiana Moreira Mar ${ }^{1 *}$, Matheus Moraes Biondo ${ }^{1}$, Edgar Aparecido Sanches ${ }^{1}$ \\ Pedro Henrique Campelo ${ }^{2}$ and Jaqueline de Araújo Bezerra ${ }^{3}$ \\ ${ }^{1}$ Laboratory of Nanostructured Polymers (NANOPOL), Federal University of Amazonas, Brazil \\ ${ }^{2}$ Faculty of Agrarian Science, Federal University of Amazonas, Brazil \\ ${ }^{3}$ Federal Institute of Education, Brazil
}

\begin{abstract}
The search for different methods of new technologies capable of helping the food industry has become increasingly attractive, since it is in constant growth and development, gaining notoriety when it comes to health and well-being. In this way, the introduction of bioactive compounds in high-growing foods, with emphasis on techniques such as microencapsulation, since it consists of protecting the agents provided in the food, with a basic of resisting the beginning of the digestive system, which starts in the stomatognathic apparatus (chewing and swallowing), from the moment it is consumed, reaching the specific location of the human body to perform its function. The aim of this literature review was to address the importance of microencapsulation technology for bioactive compounds in foods. Studies in the area of microencapsulation of microorganisms and bioactive compounds are a promising technology in the food and pharmacological areas, bringing positive results as an ally in the development of adequate foods and maintenance of human health.
\end{abstract}

Keywords: Bioactive compound, Food industry; Microencapsulation

\section{Mini Review}

Encapsulation is a technology of packaging particles (liquid, gaseous or solid) in edible capsules and is considered a promising tool for the optimization of molecules and living cells through particles [1]. The carrier material that forms the capsule is known as an encapsulant, wall or cover material. Encapsulated material has several names such as encapsulated agent, active agent, core or filler [2]. In addition to the variety of reasons in the microencapsulation process, bioactive ingredients are encapsulated for better durability and functionality, preventing their degradation from external agents, in addition to the microencapsulation process ensuring the control of their delivery to the gastrointestinal tract, i.e., microencapsulation in Food aims to preserve valuable and sensitive components, protecting them from adverse environmental conditions such as oxygen, heat and water.

This method helps protect many functional core compounds, such as antioxidants, enzymes, polyphenols and micronutrients; the delivery of these compounds to the controlled destination location; and the protection of an unfavorable environment $[3,4]$. The governing principles for achieving desirable product stability can be managed by controlling the microcapsule structure, regardless of whether the products relate to flavors, sweets, coffee, probiotics, health foods, vitamins, minerals or enzymes [5]. Currently, food products are gaining strength due to their potential for extracting bioactive compounds mainly due to the development of new products with nutritional and functional values and benefits.

The Amazon region is well known for the rich biodiversity of fruit species containing large amounts of bioactive compounds, among which the antioxidant properties of tropical fruits stand out, in which they have different levels of vitamins $\mathrm{C}$ and $\mathrm{E}$, in addition to carotenoids, 
flavonoids and other polyphenols. From the evaluation of different drying methods (lyophilization and spray-dry) and carriers (gum arabic and inulin) in microcapsules, the characterization of the powder and stability of the bioactive compounds of the extract of Hibiscus acetosella during storage, revealed characteristic signs of the acid Caffeoyl hydroxycitric, its half-life proved that the powders constituted by gum arabic and recovered by the freezedrying process had better protection and retention of bioactive compounds [6]. Encapsulated bioactive compounds obtained through the juices of the species of Cldemia japurensis and Cldemia hirta encapsulated in maltodextrin of different dextrose equivalents showed microparticles with good antioxidant properties, where their Encapsulation Efficiency (EE) ranged from 97.0 to $99.8 \%$, respectively [7].

Antioxidant compounds, found in fruits and vegetables, are extremely important substances for the maintenance of the body, providing protection and health benefits. Therefore, the increased consumption of both fruits and vegetables should be encouraged, since several compounds present in the plant cell protect against various diseases, in addition to providing a quality of life. The juice of Eugenia punicafolin species was encapsulated in microcapsules produced with dextrose equivalent to the encapsulation efficiency of the system was found around $89.7 \%$, where the NMR spectra revealed the presence of responsible 0 -glycosylated flavonoids (quercitrin and myricitrin) due to its high potential for antiglycant and antioxidant activities [8]. There are functional foods and beverages found in conventional everyday meals, and they are made up of ingredients that have chemical properties of great physiological potential, as they show the regulatory capacity of bodily functions, reducing the risk of developing diseases.

Quercetin is a classic example of an important flavonoid, found distributed in the plant kingdom and can be consumed through daily food. Quercetin's mechanisms of action have been gaining prominence in the scientific space, as it demonstrates a collaborative role in the prevention of injuries caused by risk factors, such as chronic diseases. Cell microencapsulation products are at an advanced stage of development, with some being tested in clinical trials. Several are expected to reach the market in the coming years [9]. This review article aims to provide detailed and useful information about the benefit of the microencapsulation process currently available to the food industry and developed by the pharmaceutical industry.

\section{References}

1. Nedovic V, Kalusevic A, Manojlovic V, Levic S (2011) An overview of encapsulation technologies for food applications. Procedia Food Science 1: 1806-1815.

2. Melo BD, Machado EC, Moura DF, Oliveira MHM, Rocha TA, et al. (2018) Potential application of microencapsulation in the food industry. International Journal of Advanced Research 6(12): 956-976.

3. Kwak HS (2014) Overview of nano and microencapsulation for foods. In: Nano-and Microencapsulation for Food. John Wiley \& Sons Ltd, USA, pp. 1-14.

4. Lee Y, Mijan MAL, Ganesan P (2013) The physicochemical properties of yoghurt supplemented with microencapsulated peanut sprout extract, a possible functional ingredient. International Journal of Dairy Technology 66(3): 417-423.

5. Sobel R, Versic R, Gaonkar AG (2014) Introduction to microencapsulation and controlled delivery in foods. In: Microencapsulation in the Food Industry. Elsevier Inc, Netherlands.

6. Moreira J, Souza L, Cristina A, Ferreira V, Irene M, et al. (2020) Bioactive compounds-rich powders: Influence of different carriers and drying techniques on the chemical stability of the Hibiscus acetosella extract. FAO 360: 383-391.

7. Mar JM, Silva LS, Rabelo MS, Muniz MP, Nunomura SM, et al. (2020) Encapsulation of Amazonian blueberry juices: evaluation of bioactive compounds and stability. Lwt 124: 109152.

8. Ramos AS, Mar JM, Silva LS, Acho LDR, Silva BJP, et al. (2019) Pedraume caá fruit: An Amazon cherry rich in phenolic compounds with antiglycant and antioxidant properties. Food Research International 123: 674-683.

9. Mendez TBL, Vizcaino ES, Pedraz JL, Hernandez RM, Orive G (2021) Cell microencapsulation technologies for sustained drug delivery: Clinical trials and companies. Drug Discovery Today 26(3): 852-861. 